\title{
Comparative environmental and social life cycle assessments of off-shore aquaculture rafts made in ultra-high performance concrete (UHPC)
}

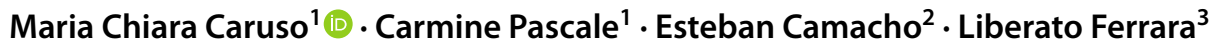

Received: 9 April 2021 / Accepted: 13 December 2021 / Published online: 18 February 2022

(c) The Author(s) 2022

\begin{abstract}
Purpose This paper aims to compare the environmental and social impacts of three types of rafts for mussel farming in Spain. These structures, traditionally made of wood, have a short lifespan and, because of their service conditions, require frequent maintenance in order to be fully operational. An innovative solution made with ultra-high performance concrete (UHPC) was developed in 2016 by RDC, being at the base of the pilots of the EU-funded project ReSHEALience (H2020-GA760824). Methods In order to quantify the environmental and social impacts generated by alternative solutions for the aquaculture raft, a life cycle approach has been used. The life cycle assessment methodology, according to ISO 14040 and ISO 14044 standards, has been used for the evaluation of the environmental impacts, while the social life cycle assessment (SLCA) methodology, according to the Guidelines for SLCA of Products and the social impact assessment method developed by Ciroth and Franze (2011), has been used for the evaluation of the social impacts: the same functional unit and the same stages of the life cycle to be included in the study has been set for the alternative solutions.

Results and discussion Based on the LCA results, derived from the system boundary described in the "Goal and scope" section for the mussel aquaculture structures, the highest environmental impacts in the cradle-to-grave analysis are generated by the Traditional Raft with maintenance based on the periodic application of paints; the lowest environmental impacts are generated by the Traditional Raft with maintenance based on the progressive replacement of the damaged logs, while the Innovative Raft has an intermediate behavior in terms of environmental impact generation. Based on the S-LCA results, it can be stated that both the solutions generate high impacts; nevertheless, the Innovative solution has a slight lower impact than the Traditional solutions, which could be lowered if some precautions in the society policy are taken. Social hot-spots are identified in order to help reducing the overall social impacts.

Conclusions In conclusion, it can be stated that, from both the environmental and social points of view, the Traditional Solutions for the aquaculture raft are the most "impactful," especially when the maintenance is based on paint application. The use of innovative concretes allows to build longer lifespan rafts with minimum (or no) need of maintenance. Moreover, the behavior of new companies is more attentive to social aspects related to their activities and has a margin of improvement, when compared to traditional companies.
\end{abstract}

Keywords Ultra-High Durability Concrete · Comparative Life Cycle Assessment · Comparative Social Life Cycle Assessment . Infrastructure durability · Infrastructures in extremely aggressive exposures · Durability of structures

\section{Introduction}

Last years have been characterized by increasingly frequent and more alarming events highlighting and denouncing the

Communicated by Holger Wallbaum

Maria Chiara Caruso

mariachiara.caruso@stress-scarl.it

Extended author information available on the last page of the article burden of our "development model" on the health of the planet environment. The social matter is also a constant critical issue, given the social accidents currently occurring, related, e.g., to discrimination and freedom violations. A large number of funding initiatives have been and are 
addressing the fulfillment of the UN Sustainable Development Goals, in particular in the construction sector, which, in EU and worldwide as well, significantly contributed to the overall environmental (European Commission 2013a) and social impacts, including 18 million direct jobs (European Commission 2016). The European Commission (EC) is strongly committed in reducing the environmental, economic and social impacts of human activities also through massive investments in research projects. The EU-funded ReSHEALience Project (GA no. 760824) aims at reducing the impacts of concrete structures used in extremely aggressive environments, such as under acid, chloride, and low-temperature attacks, by enhancing their durability through the use of innovative ultra-high durability concretes (UHDCs). The UHDC, as per definition agreed upon by the project consortium, is a fiber-reinforced ultra-high performance concrete, i.e., featuring a strain-hardening behavior in tension, with the addition of micro- and nano-constituents aimed at extending the material and structural durability even in extremely aggressive structural service scenarios, including environmental exposures and cracked state (Serna et al. 2019; Criado et al. 2020; Lo Monte and Ferrara 2020, 2021; Cuenca et al. 2020, 2021a). To this purpose, in the framework of the project, different "UHDC mixes" have been developed, considering the availability of local constituents and the structural service scenario in which they were intended to serve, with reference to six pilots which have been built and are at the present being monitored (Fig. 1) (Ferrara et al. 2019). Three of the six pilots are located in marine environment, which represents the location with high potential for sustainable jobs and growth (the so-called Blue Growth). Indeed, the EU Blue Economy Report (European Commission 2020) states that the established sectors of the EU Blue Economy directly employed close to 5 million people and generated around $€ 750$ billion in turnover and $€ 218$ billion in gross value added in 2018 .
The present paper aims at presenting the improved environmental and social impacts of the innovative offshore aquaculture raft, designed by Research and Development Concretes (RDC) and produced by Prefabricados Formex (PREFFOR), in Spain. Indeed, Spain is one of the most important musselproducing countries (Irribaren 2010) and mussels are mainly cultivated in floating structures, in long-lines and, to a lesser extent, lying on fixed structures on the sand and naturally attached to coastal rocks (Tirado and Macias 2006). This work focuses on the comparison between an innovative floating structure, based on RDC concept and design and completely made with the concretes studied in the ReSHEALience Project, and traditional rafts made in eucalyptus wood, that are still currently the most used solution on the Galician coasts, which produce $45 \%$ of the EU mussels. Precisely the offshore area is in O Grove, having an average salinity of $34 \mathrm{gr} / \mathrm{l}$, significant waves height of $3.5 \mathrm{~m}$ with a period of $10 \mathrm{~s}$ maximum water currents of $1 \mathrm{~m} / \mathrm{s}$ (Meteogalicia) and maximum wind gusts of $140 \mathrm{~km} / \mathrm{h}$ (Puertos del Estado). The comparison is made considering the same reference service life (RSL), which has been fixed equal to 50 years. Indeed, 50 years is the lifetime fixed for the ultra-high performance concrete (UHPC) solution, which is proved by several studies on the durability of UHPC materials, accelerated tests and innovative design methodologies incorporating degradation mechanisms into structural design algorithms (Al-Obaidi et al. 2020; Cuenca et al. 2020; Cuenca et al. 2021a; Lo Monte and Ferrara 2021; Cuenca et al. 2021b; and Dookstami et al. 2021). Moreover, the present UHPC solution has been designed according to the French Norms of UHPC NF P18-470 (2016) and NF P18-710 (2016). The life cycle assessment and the social life cycle assessment of the alternative solutions will be presented in the following sections and the less impactful solution will be identified. Some studies exist on the environmental assessment in the mussel farming. Irribaren (2010) studied the potential environmental
Fig. 1 The ReSHEALience project pilots

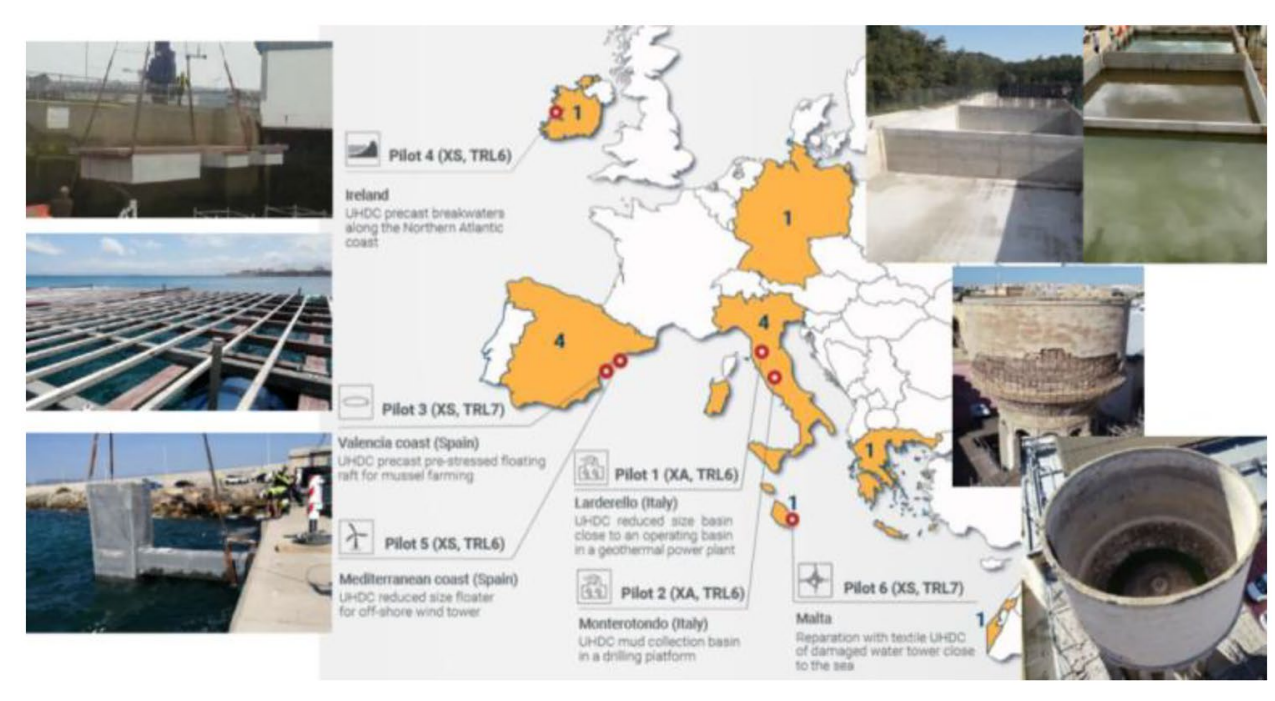


impacts linked to mussel aquaculture, including all the activities performed in the raft, including construction, operation and maintenance of the traditional (wooden) raft, but excluding the treatment of end-of-use materials from capital goods because of the lack of reliable information. Considering a raft lifetime of around 20 years, Irribaren (2010) showed the results considering the "capital goods" and the "operation activities" demonstrating the importance of considering capital goods as an impact source within mussel aquaculture. Similar results have been also provided by Tamburini et al. (2020), even if the mussel farming is performed through a series of vertical oriented ropes attached to parallel cables suspended by buoys located on the sea surface, called "longlines." The authors concluded that if the main processes in mussel farming are considered (including the seed procuring and socking, the growing and re-socking, the harvesting and transport from farm to land and the depuration and packaging), the main contributors to the environmental impact values for all categories are the capital goods such as boats and long-lines. Under the social point of view, Ozolina and Kokaine (2019) studied the socioeconomic impact of mussel farming in coastal areas of Baltic Sea, gathering the information on stakeholders views on the key issues of mussel farming through questionnaires; the study included some general social indicators, such as salary and wages, demography and social culture. General information on the social aspects of mussel production have also been studied by the Republic of South Africa (2017), highlighting that several social benefits including employment, income and food security, which are particularly important to poor, rural coastal communities worldwide can result from aquaculture. Nevertheless, these studies do not refer to a particular farming procedure, but are generally related to the aquaculture processes.

\section{Methodologies}

The identification of the environmental and social impacts is performed according to a life cycle approach; in particular, the life cycle assessment (LCA) methodology is used for the evaluation of the environmental impacts and the social life cycle assessment (SLCA) is used for the evaluation of the social impacts. This means that the assessment is performed considering the stages of the product's life cycle, starting from the extraction and production of raw materials till its End-of-Life (from cradle to grave). Both the methodologies derive from the ISO 14040 (2006), which defines the four steps needed to perform the analysis: the Goal and Scope definition, where the functional unit (FU) of the case under investigation and the system boundaries of the product life cycle are set; the Inventory of all the inputs and outputs needed to perform the analysis; the Impact Assessment for the quantification of the impacts; the Interpretation of the results and the suggestions for gaining better performances. LCA has been performed according to ISO 14040 (2006), ISO 14044 (2006) and CEN. EN 15804 (2013), SLCA has been performed according by the Guidelines of the S-LCA methodology UNEP-SETAC (2009), the related methodological sheets UNEP - SETAC (2013) developed by UNEP/ SETAC and the methodology for the social impact assessment by Ciroth and Franze (2011). Regarding the S-LCA methodology, the authors are aware that a new version of the methodology has been recently released Achten et al. (2020); nevertheless, the SLCA activities have been completed in the same period, following the previous approach.

\section{Description of the alternative solutions}

The environmental and social comparison is performed for three alternative solutions for the offshore aquaculture raft:

- Traditional raft, option 1

- Traditional raft, option 2

- Innovative raft

The three alternatives have the same dimensions in plan, $27 \mathrm{~m} \times 20 \mathrm{~m}$, which depends on the type of water (larger where the water has high concentration of phytoplankton) and the same structural concept (maximum bending moment of a single beam equal to $250 \mathrm{kNm}$ and design safety factors ranging between 1.3 and 1.5, as reported in López et al. (2017)). The main differences among the alternative solutions are the platform structural materials and the related maintenance activities.

The traditional rafts (Fig. 2) are made of wooden beams; in particular, each raft consists of 6 primary beams, $20 \mathrm{~m}$ long, made of eucalyptus wood with a $37 \mathrm{~cm} \times 37 \mathrm{~cm}$ cross section and 10 secondary beams, $27 \mathrm{~m}$ long, and with cross section of $25 \mathrm{~cm} \times 30 \mathrm{~cm}$. Moreover, the structure has two external beams $(20 \mathrm{~m}$ long and with a $25 \mathrm{~cm} \times 30 \mathrm{~cm}$ cross section) and one central beam ( $8 \mathrm{~m}$ long with a $35 \mathrm{~cm} \times 35 \mathrm{~cm}$ cross section), which is used to connect the steel mooring chain. Finally, $10 \mathrm{~cm} \times 10 \mathrm{~cm}$ wooden joists are nailed all over the platform on the secondary beams and perpendicular to them. The $12-\mathrm{m}$ ropes that carry the mussels will hang from them. The platform floats thanks to the buoyancy of six steel floaters protected with glass fiber reinforced polyester. The rafts are moored using generally one to three concrete blocks that sum a weight of up to 30 $\mathrm{t}$, which are connected to the raft with a steel chain that absorbs the environmental forces acting as a heavy catenary. The main difference between the two traditional solutions is the strategy to maintain the structure: the first system suggests a maintenance replacing progressively the primary and secondary beams; while the second suggests a maintenance 
Fig. 2 Traditional offshore aquaculture raft

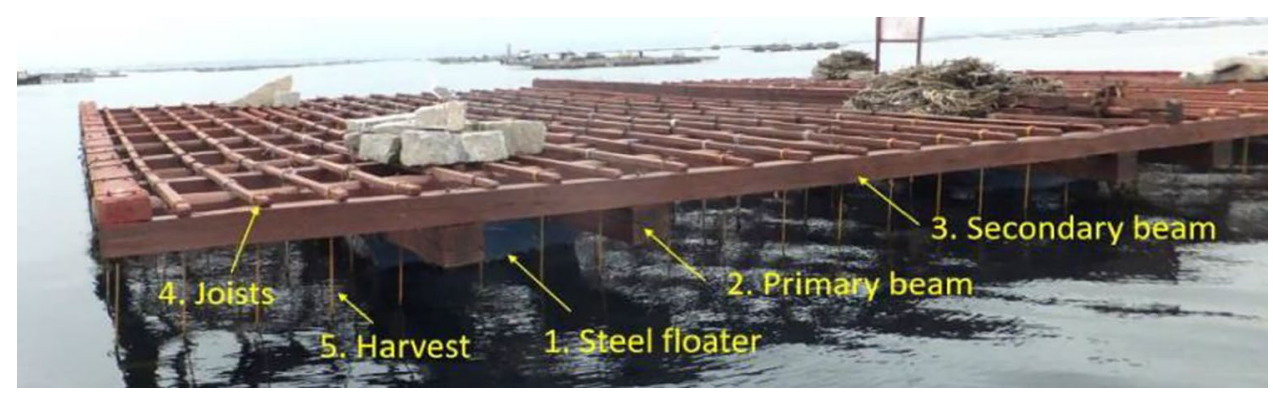

applying periodically a protective paint to the primary and secondary beams.

The innovative rafts (Fig. 3) are made of UHPC; they consist of 6 primary beams with a cross section equal to $25 \mathrm{~cm} \times 23 \mathrm{~cm}$ and 10 secondary beams with a cross section equal to $25 \mathrm{~cm} \times 23 \mathrm{~cm}$. The beams are pre-stressed and have a hollow core cross section; they have the same length as the beams in the traditional raft. The other components, such as the central beam, the joists, the steel floaters and related connections, the mooring concrete blocks and the steel chain, are the same of the traditional alternatives. UHPC can be cast considering different mix designs. The mix design used in the present assessment is shown in Table 1. It includes crystalline admixture (Penetron Admix ${ }^{\circledR}$ ) as stimulators of autogenous healing and nano-scale functionalizing constituents for enhanced durability.

\section{Common goal and scope}

In order to perform a comparative environmental and social assessment, a common goal and scope has to be defined for both the analysis and for the three alternative solutions. Therefore, a common functional unit and same life cycle stages modules, according to CEN. EN 15804 (2013), are set. The UHPC and the wooden aquaculture rafts compared in the present LCA and S-LCA are designed to farm the same amount of mussels and other mollusks, with an average production of $70 \mathrm{t}$ each. Therefore, the functional unit is "the whole raft, used for the production of $70 \mathrm{t}$ of mussels in marine environment exposed to variable sea current stresses."

The system boundary has been defined according to the CEN. EN 15804 (2013) modules, which are reported in Table 2, where the " $\mathrm{X}$ " indicates that the module is included, and the "NI" indicates that the module is not included. Therefore, the stages included in the present assessment are as follows: the production stages (modules A1, A2, and A3); the transport from manufacturing to the construction site (A4); the raft installation (A5); the maintenance operations (B2); the deconstruction of the raft (C1); the transport of the raft to the landfill site or the recycling plant (module $\mathrm{C} 2$ ); the end of life of the raft (modules C3 and C4); and the possible reuse/recovery/recycling of the raft of parts of it (Module D).

Moreover, the raft components that do not change from the traditional to the alternative solutions are not included in the analysis, given the comparative aim of the latter; therefore the two external wooden beams, the central wooden beam, the joists, the steel floaters and related connections
Fig. 3 Innovative offshore aquaculture raft

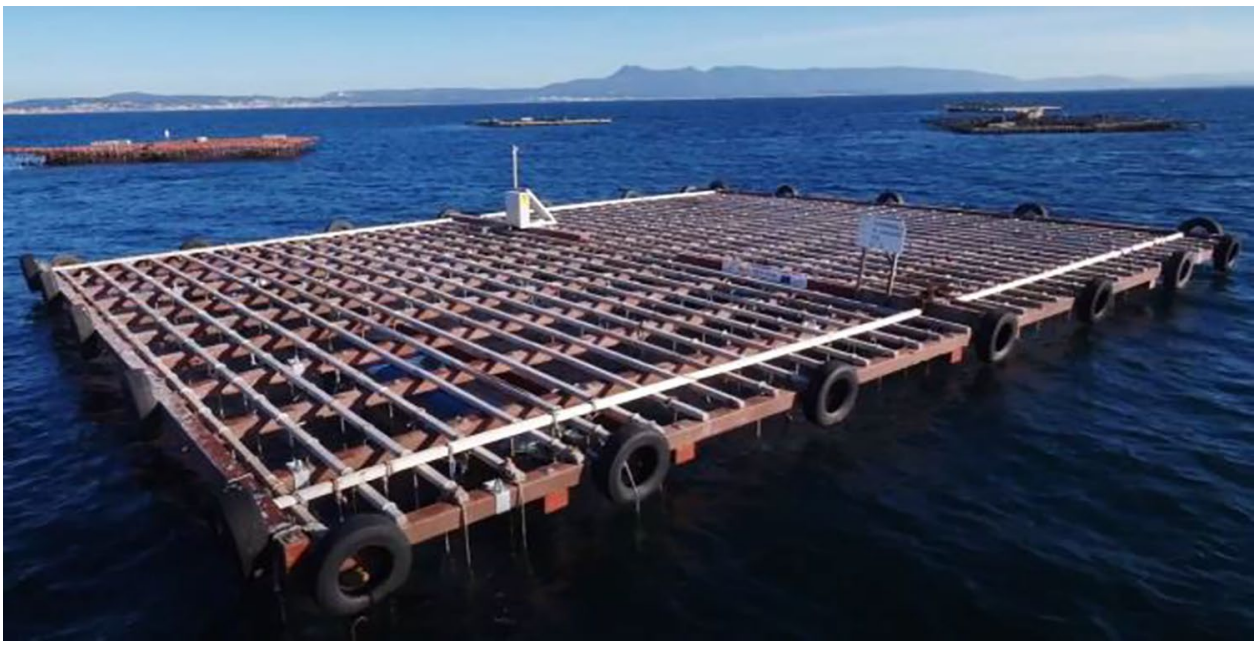


Table 1 UHPC mix design

Mix design UHPC (INN1 and INN2)

Cement

Cement I 42.5 R-SR $800 \mathrm{~kg} / \mathrm{m}^{3}$

Silica fume

$175 \mathrm{~kg} / \mathrm{m}^{3}$

Siliceous sand

$0-0.6 \mathrm{~mm} 1062 \mathrm{~kg} / \mathrm{m}^{3}$

Steel Fibers

Superplasticizer

$13 / 0.2 \mathrm{~mm} / \mathrm{mm} 160 \mathrm{~kg} / \mathrm{m}^{3}$

Water

$30 \mathrm{~kg} / \mathrm{m}^{3}$

Crystalline admixture

$160 \mathrm{~kg} / \mathrm{m}^{3}$

$\mathrm{w} / \mathrm{c}$

$6.4 \mathrm{~kg}(0.8 \%$ of cement content $)$

$0.200 \mathrm{~kg} / \mathrm{m}^{3}$

$\mathrm{w} / \mathrm{b}$

$0.164 \mathrm{~kg} / \mathrm{m}^{3}$

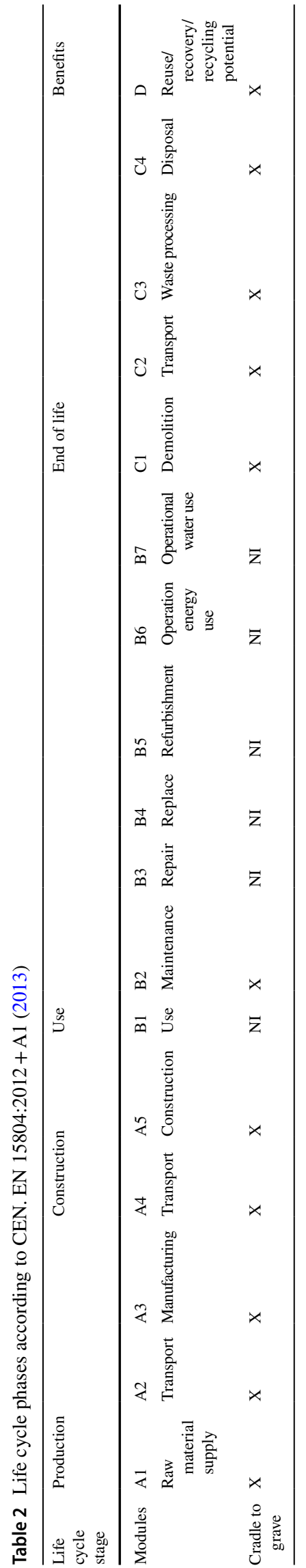

(i.e., steel nails and nylon ropes), the three concrete cubes and the steel chain, have been excluded from the analysis.

A more detailed explanation of the system boundary is reported here after for all the alternatives.

For the wooden raft, the A1 stage includes the supply of logs of old and wide eucalyptus trees, which are selected and cut down in forests in order to reach the desired dimensions, and the supply of steel for nails and bolts. For the A2 stage, referred to logs that are loaded on trucks and transported to the location where the raft will be assembled: $50 \mathrm{~km}$ of distance is considered. The A3 stage, i.e., manufacturing, is not considered because the cut logs are directly sent to construction site, where they are assembled. For the A4 stage, only the transportation of the steel nails is considered. In the A5 stage, i.e., construction/installation, the primary and secondary beams are moved from the truck with a tractor and put in an intertidal zone, in order to be assembled at low tide. At first the floaters are placed and then the beams are positioned and connected through nails and struts trough manual operations performed by three workers; the installation ends when the tide rises and a vessel pulls the raft for $6 \mathrm{~km}$ to install it in its final location, on the seawater. Regarding maintenance (B2 stage), as already mentioned, two options are contemplated. Option 1 refers to the $\log$ substitution: one primary beam and one secondary beam are replaced with a yearly frequency, starting from the seventh operational year. In this case, the following processes are considered: the extraction and production of new cut $\operatorname{logs}$, the beams loading on truck, the transport to the construction site, the beams unloading from truck, the transport of beams and workers to the raft by vessel, the beams substitution through manual operations, the transport of old beams and workers back to the shore, the transport of old beams to the new destination, and, finally, the waste treatment of old beams. Option 2 refers to the application of protective paint: the paint is applied yearly for the first 3 years and from the seventh to the eleventh year, when the raft reaches the end of its lifetime. In this case, the following processes are considered: the transport of two workers and paint to the 
raft by vessel and the manual paint application. Moreover, in the maintenance phase, monthly raft inspections are also planned: indeed, the farmers inspect the raft and re-screw the bolts if screw loosening occurs. Regarding $\mathrm{C} 1$ stage, the rafts are towed to the shore and decommissioned progressively, using the inverted assembling operations. The C2 stage includes the transport of the wooden waste to a new destination and of the steel waste to disposal; for both the transportations, a distance of $50 \mathrm{~km}$ is considered. Waste processing (C3 stage) is not performed, and disposal (C4 stage) is considered for the steel elements. For the D stage, the wood of the primary and secondary beams is reused for other applications or burned.

Regarding the UHPC raft, the A1 stage includes the supply of UHPC concrete starting from the virgin raw materials listed in Table 1; the production of steel for pre-tensioning; the production of EPS for cross section lightening; the production of HDPE for beams connections. For the A2 stage, different distances to the manufacturing site are considered for each raw material: indeed, a distance of $30 \mathrm{~km}$ is considered for the cement, the sand, the silica fume, the prestressing steel, the EPS and the HDPE; a distance of $100 \mathrm{~km}$ is considered for the steel fibres and the superplasticizer and the crystalline admixture. Regarding the A3 stage, the primary and the secondary beams, made in UHPC, are manufactured in a precast plant; since the UHPC cannot be nailed, a high-performance synthetic element crossing the section is allocated in the position of the screw; moreover, the molds are realized to manufacture four beams at the same time, and oil for demoulding is applied on the surface. EPS is then added to close the void in the core of the beams. Steel is placed and pre-stressed with a pre-stressing machine, while concrete is mixed and then the beams are cast. $24 \mathrm{~h}$ after pouring, the pre-stressed strands can be cut (with an approximate production of $20 \%$ of steel waste) and the beams are extracted from the mould and stored in the plant. Regarding the A4 stage, two special trucks are required to transport all the beams of the UHPC raft for approximately $1000 \mathrm{~km}$. For the construction/installation (A5 stage), a 20-t crane is used to move the beams; then primary and secondary beams are connected through nails inserted in high-performance synthetic elements using an electric drill, while the joists are connected through proper nails and struts with manual operations. The whole raft is finally put in the seawater though the use of a 500-t crane and located at an average distance of $6 \mathrm{~km}$ from the shore towing with a boat. Maintenance during UHPC raft lifespan is not necessary; therefore, this stage is not included in the assessment. Regarding the $\mathrm{C} 1$ stage, the raft is moved on the shore and the deconstruction operation is performed with a small crane, used to move the beams; the deconstruction needs around $15 \mathrm{~h}$ and is performed with an electric drill. For the $\mathrm{C} 2$ stage, depending on their state, the
UHPC beams can be reused for other structures or recycled, after their lifespan, which is fixed equal to 50 years: in the present case study, it is assumed that $50 \%$ of the beams are still in good conditions and are reused, e.g., for short bridges or fences, and, therefore, they are transported to another destination; the remaining $50 \%$ of the beams are recycled, and, therefore, they are crushed on site. Regarding the steel, the polystyrene and synthetic elements, they are sent to disposal. For the C3 stage, the $50 \%$ of the beams are crushed and then used as gravel. The disposal of the other elements is considered ( $\mathrm{C} 4$ stage). For the D stage, avoided new fine aggregate production is considered as a benefit for $50 \%$ of UHPC beams.

The sustainability comparisons will be performed considering a period equal to 50 years. Indeed, the three rafts have a different lifespans: the 1st maintenance approach of traditional raft reaches an average of 23 years lifetime; the 2 nd approach reaches 15 years lifetime; and finally, the UHPC raft is designed to be used for at least 50 years with no maintenance. This means that the wooden rafts impacts are evaluated for both solutions, considering their service lives and, before comparing them with the innovative solution, the impacts are multiplied by a factor taking into account their different lifespans.

\section{Life cycle assessment}

The evaluation of the environmental impacts has been performed through an LCA analysis, according to the followings steps: Inventory, Impact Assessment (IA) and Interpretation, as reported in the ISO 14040 (2006) and ISO 14044 (2006). Each stage is described below.

\subsection{LCA inventory}

Starting from the life cycle stage description, the inventory aims at collecting all the input and output amounts related to each process unit, including materials, energy, transportations, waste, and emissions. Data collection has been performed by quantifying the amounts of each input and output related to each process included in the life cycle modules described before. Tables 3 and 4 show the unit processes identified for each life cycle stage. The inputs and the outputs related to each unit process have been modelled with the help of Ecoinvent v3.5 database (Wernet et al. 2016) by choosing the more suitable dataset, considering, e.g., the geographical location, the technology, the age. Moreover, to model the ultra-high performance concrete, considering the mix design reported in Table 1, specific information has been collected starting from the components inventory made available by the 
Table 3 LCA inventory of traditional rafts option 1 and option 2. Identification of Ecoinvent xxx datasets

\begin{tabular}{|c|c|c|c|}
\hline \multirow[t]{4}{*}{ Production A1-A3 } & \multirow[t]{2}{*}{ Supply of raw materials } & Cut Eucalyptus wood & $\begin{array}{l}\text { Roundwood, Eucalyptus ssp. from } \\
\text { sustainable forest management, } \\
\text { under bark }\{\text { RoW }\} \mid\end{array}$ \\
\hline & & Beams loading & Excavation, skid-steer loader $\{$ GLO $\}$ \\
\hline & Transport of raw materials & Transport of beams to assembly point & $\begin{array}{l}\text { Transport, freight, lorry } 16-32 \text { metric } \\
\text { ton, euro5 }\{\text { RER }\}\end{array}$ \\
\hline & Manufacturing & Manual assembly & - \\
\hline \multirow[t]{4}{*}{ Construction A1-A4 } & Transport to building site & Transport of nails & $\begin{array}{l}\text { Transport, freight, light commercial } \\
\text { vehicle }\{\text { RER }\} \mid\end{array}$ \\
\hline & \multirow[t]{3}{*}{ Installation/construction } & Assembly of all beams & Excavation, skid-steer loader $\{$ GLO $\}$ \\
\hline & & Nails & Steel, low-alloyed $\{$ GLO $\}$ \\
\hline & & $\begin{array}{l}\text { Transport to the raft to the sea }(6 \mathrm{~km} \\
\text { from the shore) }\end{array}$ & $\begin{array}{l}\text { Transport, freight, inland waterways, } \\
\text { barge }\{\text { RER }\}\end{array}$ \\
\hline \multirow[t]{8}{*}{ Use option $1 \mathrm{B2}$} & \multirow{8}{*}{$\begin{array}{l}\text { Maintenance option 1: After } 7 \text { years, } \\
\text { logs start to be damaged, and } 2 \\
\text { logs per year are substituted (one } \\
\text { primary beam and } 1 \text { secondary } \\
\text { beam) }\end{array}$} & New beams & $\begin{array}{l}\text { Roundwood, eucalyptus ssp. from } \\
\text { sustainable forest management, } \\
\text { under bark }\{\text { RoW }\} \mid\end{array}$ \\
\hline & & $\begin{array}{l}\text { Transport of new beams to assembly } \\
\text { point }\end{array}$ & $\begin{array}{l}\text { Transport, freight, lorry } 16-32 \text { metric } \\
\text { ton, euro5 }\{\text { RER }\}\end{array}$ \\
\hline & & Loading and un-loading of new beams & Excavation, skid-steer loader $\{\mathrm{GLO}\}$ \\
\hline & & $\begin{array}{l}\text { Transport of new beams and workers to } \\
\text { the raft }\end{array}$ & $\begin{array}{l}\text { Transport, freight, inland waterways, } \\
\text { barge }\{\text { RER }\}\end{array}$ \\
\hline & & $\begin{array}{l}\text { Transport of old beams and workers at } \\
\text { the shore }\end{array}$ & $\begin{array}{l}\text { Transport, freight, inland waterways, } \\
\text { barge }\{\text { RER }\}\end{array}$ \\
\hline & & $\begin{array}{l}\text { Transport of old beams to new destination. } \\
\text { Hyp: } 50 \mathrm{~km} \text { distance }\end{array}$ & $\begin{array}{l}\text { Transport, freight, lorry } 16-32 \text { metric } \\
\text { ton, euro5 }\{\text { RER }\}\end{array}$ \\
\hline & & Wood of old beams to be reused & $\begin{array}{l}\text { Avoided Sawlog and veneer log, } \\
\text { softwood, debarked, measured as } \\
\text { solid wood }\{\text { RER }\}\end{array}$ \\
\hline & & Inspections and manual rescrew & $\begin{array}{l}\text { Transport, freight, inland waterways, } \\
\text { barge }\{\text { RER }\}\end{array}$ \\
\hline \multirow[t]{3}{*}{ Use option 2 B2 } & \multirow{3}{*}{$\begin{array}{l}\text { Maintenance option 2: Paint is } \\
\text { applied each year during the first } \\
3 \text { years; later it is not painted } \\
\text { until year } 7 \text { (for } 4 \text { years), when it } \\
\text { is painted again every year until } \\
\text { the end of its lifetime (year 15) }\end{array}$} & $\begin{array}{l}\text { Transport of paint and workers to the } \\
\text { raft }\end{array}$ & $\begin{array}{l}\text { Transport, freight, inland waterways, } \\
\text { barge }\{\text { RER }\}\end{array}$ \\
\hline & & Paint & $\begin{array}{l}\text { Alkyd paint, white, without solvent, in } \\
60 \% \text { solution state }\{\text { RER }\}\end{array}$ \\
\hline & & Inspections and manual rescrew & $\begin{array}{l}\text { Transport, freight, inland waterways, } \\
\text { barge }\{\text { RER }\}\end{array}$ \\
\hline \multirow[t]{5}{*}{ End of life C1-C4 } & \multirow[t]{2}{*}{ Deconstruction and demolition } & Transport of old raft to the shore & $\begin{array}{l}\text { Transport, freight, inland waterways, } \\
\text { barge }\{\text { RER }\}\end{array}$ \\
\hline & & Beams unloading & Excavation, skid-steer loader $\{$ GLO $\}$ \\
\hline & \multirow[t]{2}{*}{ Transport } & Transport beams to new destination & $\begin{array}{l}\text { Transport, freight, lorry } 16-32 \text { metric } \\
\text { ton, euro5 \{RER }\}\end{array}$ \\
\hline & & Transport of steel nails to disposal & $\begin{array}{l}\text { Transport, freight, light commercial } \\
\text { vehicle }\{\text { RER }\} \mid\end{array}$ \\
\hline & Disposal & Steel nails disposal & Scrap steel $\{$ Europe without Switzerland $\}$ \\
\hline Benefits D & Reuse, recovery, recycling potential & Wood to be reused & $\begin{array}{l}\text { Avoided "Sawlog and veneer log, } \\
\text { softwood, debarked, measured as } \\
\text { solid wood }\{\text { RER }\} \mid\end{array}$ \\
\hline
\end{tabular}

involved ReSHEALience consortium partners and, therefore, precise analysis on these components have been performed.

The life cycle stages have been modelled in Simapro v9.1 software (Goedkoop et al. 2016), which includes updated life cycle inventory (LCI) databases, such as Ecoinvent (Wernet et al. 2016), ELCD (European
Commission 2013b), USLCI (U.S. Life Cycle Inventory 2009), and updated LCA methodologies for impact assessment.

Once all the unit processes have been modelled, the environmental impacts can be quantified through the chosen methodology for Impact Assessment. 
Table 4 LCA inventory of innovative raft

Production A1-A3 Supply of raw materials

Transport of all raw materials to production site

\section{Manufacturing}

Construction A1-A4 Transport to building site

Installation/construction

Use B1-B7
UHPC

Cement 42,5 R/SR

Sand

Silica Fume

Plasticizer Sika $20 \mathrm{HE}$

Short steel fibers (13/0.2)

Water

Penetron Admixture

Pre-stressing steel

Polystyrene

High-performance synthetic element

Transport of all raw materials to production site
Cement, Portland \{Europe without Switzerland\}

Silica sand $\{$ GLO $\}$

Silica fume, densified $\{$ GLO $\}$ |

Chemical, organic $\{$ GLO $\} \mid$

Steel, low-alloyed $\{$ RER $\}$ ।

Wire drawing, steel \{RER $\}$ ।

Tap water $\{$ RER $\}$ |

Trade secret material

Iron and steel, production mix

Polystyrene, expandable \{RER $\}$ |

Polyethylene, HDPE, granulate, at plant/ RER

Transport, freight, lorry 16-32 metric ton, euro5 \{RER\}।

Transport, freight, lorry $>32$ metric ton, euro5 \{RER\}।

Transport, freight, lorry 3.5-7.5 metric ton, euro5 \{RER\}।

UHPC production - energy for concrete Electricity, medium voltage $\{$ RER $\}$ | mixing

Pre-tensioned Beams production

Mold

Steel, low-alloyed $\{$ RER $\}$ Hot rolling, steel \{GLO\}।

Oil for demolding

Energy for pre-stressing

Energy for cutting pre-stressed steel

Grinder for removal of possible fibers in the corners

Crane for loading beams on the truck

Pre-stressing strands waste

Transport of waste to landfill

Transport of beams

Nails

Electric drill

Crane for loading raft on the sea + movements on the ground

Transport of raft to the sea
White mineral oil, at plant/RNA

Electricity, medium voltage $\{$ RER $\}$ |

Electricity, medium voltage $\{$ RER $\}$ |

Electricity, medium voltage $\{$ RER $\} \mid$

Excavation, skid-steer loader $\{$ GLO $\}$

Scrap steel \{Europe without Switzerland\}।

Transport, freight, lorry 3.5-7.5 metric ton, euro5 \{RER\}।

Transport, freight, lorry 16-32 metric ton, euro5 \{RER\}।

Steel, low-alloyed $\{\mathrm{GLO}\}$ ।

Electricity, medium voltage $\{$ RER $\}$ |

Excavation, skid-steer loader $\{$ GLO $\}$ ।

Transport, freight, inland waterways, barge $\{$ RER $\} \mid$ 
Table 4 (continued)

\begin{tabular}{|c|c|c|c|}
\hline \multirow[t]{10}{*}{ End of life C1-C4 } & \multirow[t]{4}{*}{ Deconstruction and demolition } & Transport of raft to the shore & $\begin{array}{l}\text { Transport, freight, inland waterways, } \\
\text { barge }\{\text { RER }\} \mid\end{array}$ \\
\hline & & Crane & Excavation, skid-steer loader $\{\mathrm{GLO}\} \mid$ \\
\hline & & Electric drill & Electricity, medium voltage $\{$ RER $\} \mid$ \\
\hline & & Crane & Excavation, skid-steer loader $\{$ GLO $\} \mid$ \\
\hline & \multirow[t]{2}{*}{ Transport } & Reuse of $50 \%$ of beams-transport & $\begin{array}{l}\text { Transport, freight, lorry } 16-32 \text { metric } \\
\text { ton, euro5 }\{\text { RER }\} \mid\end{array}$ \\
\hline & & $\begin{array}{l}\text { Transport of all other materials to } \\
\text { disposal }\end{array}$ & $\begin{array}{l}\text { Transport, freight, lorry 16-32 metric } \\
\text { ton, euro5 \{RER\}| }\end{array}$ \\
\hline & Waste processing & Recycling of $50 \%$ of beams - crane & Excavation, skid-steer loader $\{$ GLO $\} \mid$ \\
\hline & \multirow[t]{3}{*}{ Disposal } & Disposal of synthetic material & $\begin{array}{l}\text { Waste polyethylene }\{\text { RoW }\} \mid \text { treatment } \\
\text { of waste polyethylene, sanitary landfill }\end{array}$ \\
\hline & & Disposal of polystyrene & $\begin{array}{l}\text { Waste polystyrene }\{\text { RoW }\} \text { I treatment of } \\
\text { waste polystyrene, sanitary landfill I }\end{array}$ \\
\hline & & $\begin{array}{l}\text { Disposal of steel (nails and pre-stressing } \\
\text { steel) }\end{array}$ & $\begin{array}{l}\text { Scrap steel }\{\text { Europe without Switzerland\}| } \\
\text { treatment of scrap steel, inert material } \\
\text { landfill }\end{array}$ \\
\hline Benefits D & Reuse, recovery, recycling potential & Avoided fine aggregate & Avoided sand $\{$ GLO $\} \mid$ \\
\hline
\end{tabular}

\subsection{LCA impact assessment and interpretation}

The evaluation of the environmental impacts generated during the life cycle of the alternative solutions for aquaculture rafts is performed according to the EPD 2018 methodology, version 1.0 (2017). The impact categories are:

- Global warming potential (GWP), measured in $\mathrm{kgCO}_{2}$, eq

- Depletion potential of the stratospheric ozone layer (ODP), measured in kg CFC-11,eq

- Acidification potential (AP), measured in $\mathrm{kg} \mathrm{SO}_{2}$, eq

- Eutrophication potential (EP), measured in $\mathrm{kg} \mathrm{PO}_{4}{ }^{3-}$, eq

- Formation potential of tropospheric ozone (POCP), measured in $\mathrm{kg}$ NMVOC

- Abiotic depletion potential - Elements, measured in $\mathrm{kg}$ $\mathrm{Sb}$, eq

- Abiotic depletion potential - Fossil resources, measured in MJ

- Water scarcity potential, measured in $\mathrm{m}^{3} \mathrm{eq}$

The life cycle assessment results are provided hereafter in comparative terms. Figure 4 shows the environmental impacts generated by each alternative solution. The highest bars represent the solutions providing the highest impacts, reaching $100 \%$ of the impact category, while the other solutions are given in percentage terms with respect to the more impactful one.

From the figure, it can be highlighted that, for all the environmental impacts, the solution providing the highest contribution is the traditional one with option 2, i.e., with maintenance made through paint application, while the lowest contribution is provided by the traditional solution with option 1, i.e., when the maintenance is made through $\log$ substitution. The innovative solution has an intermediate behavior in terms of overall environmental impact generation. In addition, the environmental impacts of the innovative solution, related to specific indicators, range from 4 times higher, in case of Eutrophication, to 20 times higher, in case of water scarcity, than the impact generated by the traditional solution, option 1 . On the other hand, the environmental impacts of the innovative solution range from $39 \%$ lower, in terms of ozone layer depletion, to $90 \%$ lower,

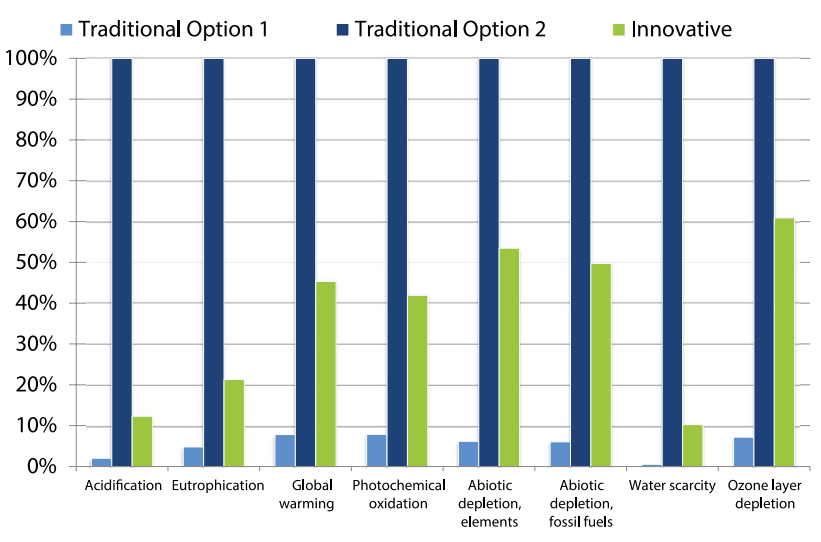

Fig. 4 Comparative life cycle assessment of alternative offshore aquaculture rafts, considering 50-year lifespan 


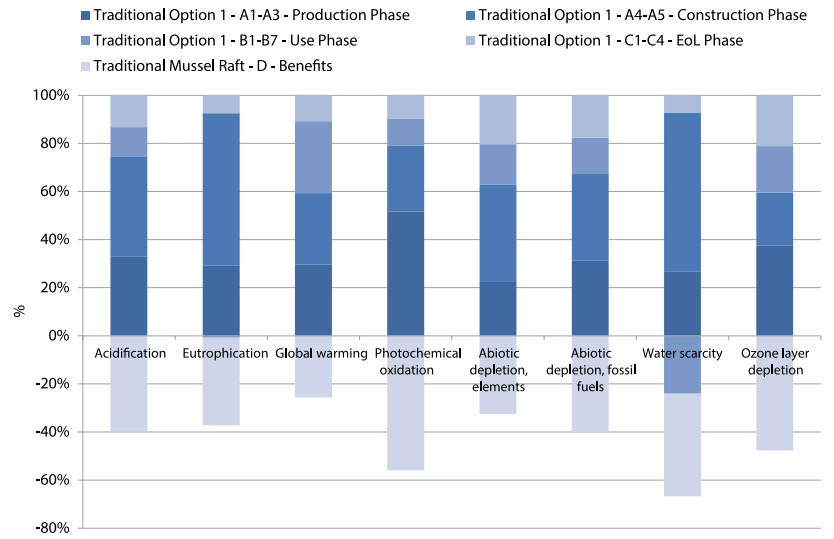

Fig. 5 Environmental impacts of the traditional aquaculture raftoption 1 , considering each life cycle stage

in terms of water scarcity, than the ones generated by the traditional solution, option 1. Moreover, it is important to point out that the LCAs of both the traditional solutions do not include the effects of the degradation of the paint and its dissolution in marine water.

A detailed analysis can be performed for each solution, in order to identify the processes being the main responsible for the environmental impacts. In the following figures, the analysis is performed for each alternative solution. Figure 5 shows the environmental results for the traditional aquaculture raft-option 1, considering all the life cycle stages. It can be noticed that, in case option 1 is considered, the contribution of the production phase to the total environmental impacts varies from $22 \%$, in case of abiotic depletion, elements, to $51 \%$, in case of photochemical oxidation; the contribution of the construction phase varies from $21 \%$, in case of ozone layer depletion, to $66 \%$, in case of water scarcity; the contribution of the use phase varies from $-24 \%$, in case of abiotic depletion, fossil fuels (due to the fact that substituted logs can be reused and therefore new saw log can be avoided), to $30 \%$, in case of global warming; the contribution of the end of life phase varies from $7 \%$, in case of eutrophication, to $21 \%$, in case of ozone layer depletion; finally, the benefits vary from $-55 \%$, in case of photochemical oxidation, to $-25 \%$, in case of global warming (the negative results mean positive effects on nature due to the avoiding of new materials).

Therefore, the highest impacts for the traditional raftoption 1 life cycle are provided by the production and construction phases. In detail, the eucalyptus $\operatorname{logs}$ are the main responsible of the impacts for production stage, being the highest contributor for 7 out of 8 environmental impacts (from 53 to $85 \%$ of the total A1-A3 stage). This is mainly caused by the power sawing process and the used diesel. For the abiotic depletion, elements, the main contributor is the transport of the logs from the forest to the assembly site
(77\% of the total A1-A3 stage); in particular, the lead for lorry maintenance is the main responsible. Considering the construction stage, the main impacts derive from the nails, contributing from 79 to $98 \%$ of the total A4-A5 environmental impacts, due to the manufacturing of low-allowed steel.

The assessment of traditional raft—option 2 is shown in Fig. 6. It can be observed that the contribution of the production phase to the total environmental impacts varies from $1 \%$, in relation to water scarcity, to $12 \%$, in relation to photochemical oxidation; the contribution of the construction phase varies from $1.5 \%$, in relation to water scarcity, to $7 \%$, in relation to Eutrophication; the contribution of the use phase varies from $79 \%$, in relation to photochemical oxidation, to $98 \%$ in relation to water scarcity; the contribution of the end of life phase varies from $0.2 \%$, in relation to water scarcity, to $4 \%$, in relation to ozone layer depletion; finally, the benefits vary from $-13 \%$, in relation to photochemical oxidation, to $-1 \%$, in relation to water scarcity (the negative results mean positive effects on nature due to the avoiding of new materials). Therefore, the maintenance phase is the main responsible of the environmental impacts generation for the traditional raft, option 2. In particular, the paint used for logs protection and preservation, due to the high application frequency and surface extension, contributes to $99 \%$ in relation to all the 8 considered environmental impacts in the maintenance phase.

Finally, for the innovative solution, Fig. 7 shows the contribution of each life cycle stage to the total environmental impacts. It can be underlined that the contribution of the production phase to the total environmental impacts generated by the innovative solution varies from $32 \%$, in relation to ozone layer depletion, to $87 \%$, in relation to water scarcity; the contribution of the construction phase varies from $12 \%$, in relation to water scarcity, to $65 \%$, in relation to ozone layer depletion; the contribution of the end of life stage varies from $1 \%$, in relation to water scarcity, to

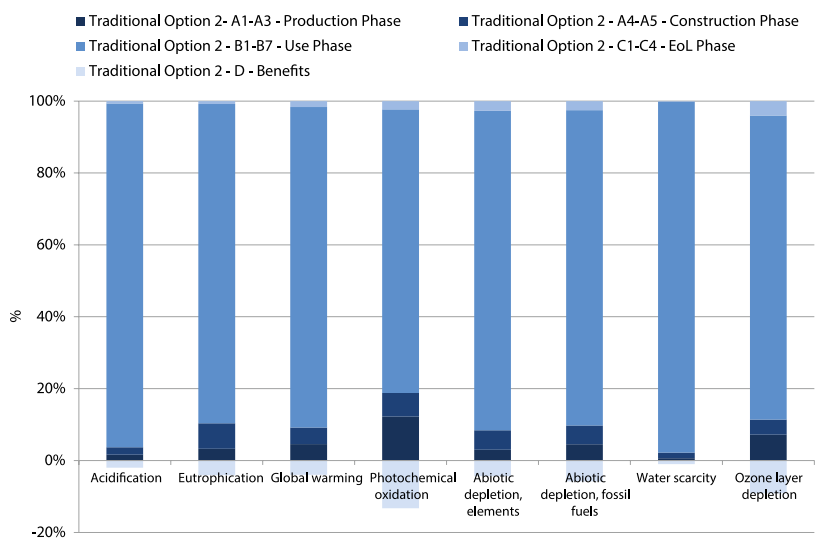

Fig. 6 Environmental impacts of the traditional aquaculture raftoption 2, considering each life cycle stage 


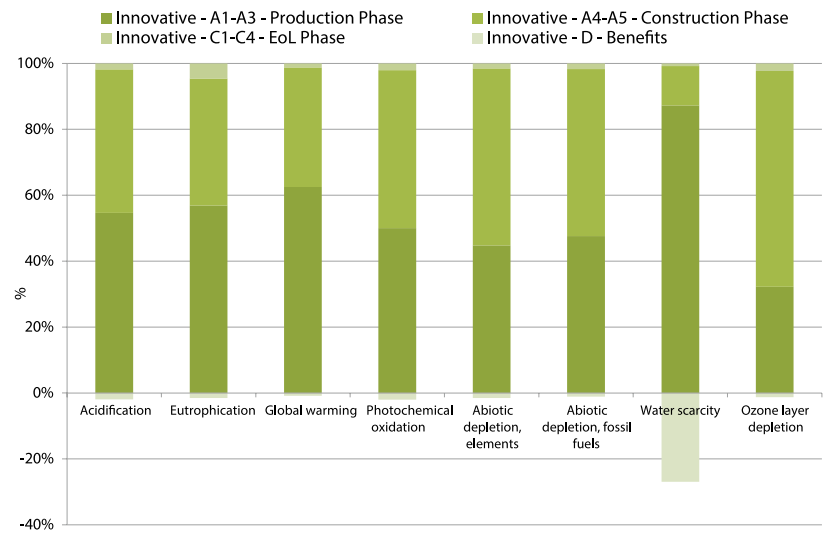

Fig. 7 Environmental impacts of the innovative aquaculture raft, considering each life cycle stage

$5 \%$, in relation to eutrophication; finally, the benefits vary from $-26 \%$, in relation to water scarcity, to $-1 \%$ in relation to global warming. Therefore, the main responsibilities of the environmental impacts generated by the innovative rafts are the production and the construction phases. In particular, the main contribution for the construction phase is provided by the transport of beams to the assembly point, contributing from $72 \%$, in relation to water scarcity, to $97 \%$, in relation to ozone layer depletion, to the whole A4-A5 stage. Moreover, the main contribution to the production phase is provided by the UHPC, varying from $72 \%$, in relation to abiotic depletion, fossil fuels, to $93 \%$, in relation to eutrophication, to the whole A1-A3 stage. Therefore, an assessment is provided for the UHPC material, in order to analyze the components that mostly affect the environmental impacts. UHPC modelling has been made considering the ingredients listed in Table 1. The results are provided in Fig. 8. Looking at the graph, it can be stated that Portland cement and steel fibers are the main responsible of the UHPC environmental impacts. Portland cement contributes from 14\%, in relation

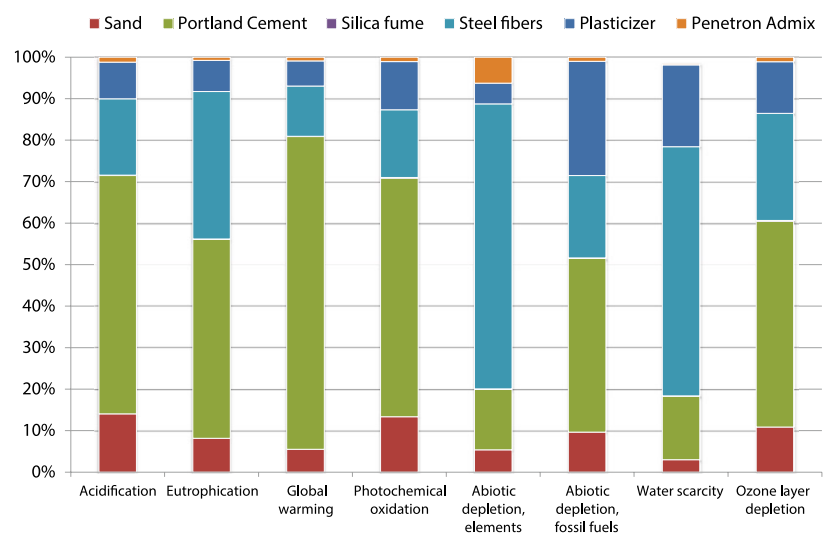

Fig. 8 LCA of the UHPC mix design to abiotic depletion, elements, to $75 \%$, in relation to global warming, to the UHPC production; steel fibers contribute from $12 \%$, in relation to global warming, to $69 \%$, in relation to abiotic depletion, elements, to the UHPC production. Relevant contributions are also provided by the sand (from 3\%, in relation to water scarcity, to $14 \%$, in relation to acidification) and by the plasticizer (5\%, in relation to abiotic depletion, elements, to $27 \%$, in relation to abiotic depletion, fossil fuels). Minor contributions to the environmental impacts generated by UHPC are provided by the crystalline admixture (from $0.2 \%$, in relation to water scarcity, to $6 \%$, in relation to abiotic depletion, elements), by the water (providing $1,5 \%$, in relation to water scarcity) and by the silica fume (less than $0.9 \%$ for all the environmental impacts).

\subsection{LCA conclusions}

The results of the life cycle assessment highlights that, when the three alternative solutions for the mussel aquaculture structures and the system boundary described in the "Goal and scope" section are considered, the highest environmental impacts are generated by the traditional raft-option 2, i.e., the wooden raft with paint application maintenance, the lowest environmental impacts are generated by the traditional raft-option 1, i.e., the wooden raft with logs substitution maintenance. Finally, the innovative raft has an intermediate behavior in terms of environmental impact generation. The high impacts produced by the traditional raft—option 2 are basically caused by the maintenance stage, during which paint is applied very frequently and on all the logs surface. The authors also highlight that LCAs of the traditional solutions do not include the effects of the degradation of the paint and its dissolution in marine water, as well as possible negative impacts on environment due to using wood logs in the long term, that would increase even more the overall impacts of both the wooden raft solutions.

\section{Social life cycle assessment}

In order to analyze social aspects associated with the alternative rafts and to evaluate the potential impacts during their lifetime, the rafts have been studied also under the social point of view, using the social life cycle assessment methodology, described in the S-LCA Guidelines (2009), the methodological sheets (2013) and the social impact assessment methodology (Ciroth and Franze 2011). In particular, the S-LCA methodology follows the same structure of ISO 14040 (2006) and, therefore, the assessment has been developed as hereafter reported:

- Step 1: Definition of the objective and application fields, i.e., function, functional unit, system boundaries. In this 
phase, together with the definition of the functional unit and the life-cycle stages to be considered, the "stakeholder categories" are defined, being a cluster of stakeholders that are expected to have shared interests due to their similar relationship to the investigated product systems. For each stakeholder category, particular themes or areas of interest, which are called "subcategories," are defined, referring to the categories of impact.

- Step 2: Inventory analysis, which involves the collection of characteristic and functional data for the development of the S-LCA analysis.

- Step 3: Evaluation of social impacts.

- Step 4: Interpretation of results and identification of critical points.

The assessment has been performed for the three alternative solutions previously described; nevertheless, for the two options of the traditional rafts, the results of the S-LCA are equal, given that the same companies are involved into the rafts life cycle. Indeed, the inventory and, consequently, the assessment, is related to 4 traditional rafts companies. Such companies have an average of approximately 6-8 employees and work in the Galician coast of Spain, managing 3337 rafts in Galicia, corresponding to $95 \%$ of the total aquaculture rafts in all the Spain. The data collected in the inventory should be considered as an average behavior of the four companies. Differently from the LCA, the last life cycle stage, i.e., the Benefit Stage (D), has not been included because stakeholders involved in possible future activities related to end of life materials could not been identified.

\subsection{S-LCA inventory}

The inventory has been performed with the support of PREFFOR and RDC companies. A list of questions has been prepared starting from the social indicators reported in each subcategory's methodological sheet (UNEP/SETAC 2013). Both the companies have previously compiled a table (Table 5), necessary to identify the relevant stakeholders and subcategories to be included in the S-LCA study and then have filled in the Questionnaires. In the figure, the " $x$ " identifies that the subcategory/stakeholder has been considered, whilst the "_" indicates that is has not been considered.

In case some subcategories or stakeholders are not included in the assessment, the related questions do not need to be replied. Some examples of questions included in the questionnaire are: regarding the "Local Community" stakeholder and the "Local employment" subcategory, "What is the percentage of local suppliers on the total of suppliers?"; regarding the "Workers" stakeholder and the "Equal opportunities/discrimination" subcategory, "Does the organization have formal policies on equal opportunities? If yes, give details"; regarding the "Value Chain Actors" stakeholder and the "Fair competition" subcategory, "Are the employees aware of the importance of compliance with competition legislation and fair competition?". Such questions collect the specific data, being the data referred to the organization involved in the process under consideration. In addition, generic data, i.e., typically country-level data, used as a screening device to identify high-risk regions, can be deduced by qualitative and quantitative data available on the data sources identified in the methodological sheet; generic data allow to understand the background where the organization works.

\subsection{S-LCA impact assessment and interpretation}

The social life cycle impact assessment is the final stage of a social life cycle assessment. It helps quantifying the potential social impacts arising from the S-LCA inventory and can be performed in two steps: first trough a performance assessment (PA) and, then, through an impact assessment (IA), as explained in the Ciroth and Franze Impact Assessment methodology (2011).

The PA is done by assigning a value from 1 (very good) to 6 (very bad) to the specific behavior of the company referred to each subcategory indicator (i.e., each reply provided to the questionnaire). The values are assigned according to the Performance Reference Points (PRP), included in the Ciroth and Franze methodology, 2011, based on internationally accepted standards (such as the ILO conventions, the ISO 26000 guidelines (2010) and the OECD Guidelines for Multinational Enterprises), goals or objectives according to conventions and best practice, etc. (for the stakeholder "Worker" and sub-category "Child labor," the PRP is "No occurrence of child labor"; for the sub-category "Fair salary," the PRP is "The wage level should ensure a decent standard of living. The payment of the minimum wage is often not sufficient. Further, companies should pay in time and do not withhold shares of the salary". Once the score is assigned to each indicator, the score of the referred subcategory can be assessed by evaluating the average of each indicator scores. Nevertheless, an additional rule is applied, which is valid for all the social impact assessment procedure: if at least one indicator in a specific subcategory is assessed with value " 6 ," the final score of the subcategory cannot be better than " 5 "; (ii) if at least one indicator in a specific subcategory is assessed with value "5," the score of the subcategory cannot be better than " 4 ," and so on. At the end of this stage, a PA score is available for each subcategory.

The IA is performed in different steps. At first, a set of six social impact categories are fixed, namely: Working Conditions (WC); Health \& Safety (HS); Human Rights (HR); Socio-Economic Repercussions (SER); Indigenous Rights (IR); Governance (G). These categories are put in relation with the subcategories by defining if the relation is strong 
Table 5 Identification of relevant stakeholders and subcategories

\begin{tabular}{|c|c|c|c|c|c|}
\hline Stakeholder & Sub-categories & $\begin{array}{l}\text { Production } \\
\text { A1-A3 }\end{array}$ & $\begin{array}{l}\text { Construction } \\
\text { A4-A5 }\end{array}$ & Use B1-B7 & EoL C1-C4 \\
\hline \multirow{9}{*}{ Local community } & Delocalization and migration & $\mathrm{x}$ & $\mathrm{x}$ & $\mathrm{x}$ & $\mathrm{x}$ \\
\hline & Community engagement & $\mathrm{x}$ & - & $\mathrm{x}$ & $\mathrm{x}$ \\
\hline & Cultural heritage & $\mathrm{x}$ & - & $\mathrm{x}$ & $\mathrm{x}$ \\
\hline & Respect of indigenous rights & - & - & - & - \\
\hline & Local employment & $\mathrm{x}$ & $\mathrm{x}$ & $\mathrm{x}$ & $\mathrm{x}$ \\
\hline & Access to immaterial resources & - & - & - & - \\
\hline & Access to material resources & $\mathrm{x}$ & $\mathrm{x}$ & $\mathrm{x}$ & $\mathrm{x}$ \\
\hline & Safe and healthy living conditions & $\mathrm{x}$ & $\mathrm{x}$ & $\mathrm{x}$ & $\mathrm{x}$ \\
\hline & Secure living conditions & $\mathrm{x}$ & $\mathrm{x}$ & $\mathrm{x}$ & $\mathrm{x}$ \\
\hline \multirow[t]{4}{*}{ Value chain actors } & Fair competition & $\mathrm{x}$ & $\mathrm{x}$ & - & $\mathrm{x}$ \\
\hline & Respect of intellectual property rights & $\mathrm{x}$ & $\mathrm{x}$ & - & $\mathrm{x}$ \\
\hline & Supplier relationships & $\mathrm{x}$ & $\mathrm{x}$ & - & $\mathrm{x}$ \\
\hline & Promoting social responsibility & $\mathrm{x}$ & $\mathrm{x}$ & - & $\mathrm{x}$ \\
\hline \multirow[t]{5}{*}{ Consumers } & Health and safety & - & - & - & - \\
\hline & Feedback mechanism & - & - & - & - \\
\hline & Consumer privacy & - & - & - & - \\
\hline & Transparency & - & - & - & - \\
\hline & End of life responsibility & - & - & - & - \\
\hline \multirow[t]{8}{*}{ Workers } & Freedom of association and collective bargaining & $\mathrm{x}$ & $\mathrm{x}$ & $\mathrm{x}$ & $\mathrm{x}$ \\
\hline & Child labor & $\mathrm{x}$ & $\mathrm{x}$ & $\mathrm{x}$ & $\mathrm{x}$ \\
\hline & Fair salary & $\mathrm{x}$ & $\mathrm{x}$ & $\mathrm{x}$ & $\mathrm{x}$ \\
\hline & Working hours & $\mathrm{x}$ & $\mathrm{x}$ & $\mathrm{x}$ & $\mathrm{x}$ \\
\hline & Forced labor & $\mathrm{x}$ & $\mathrm{x}$ & $\mathrm{x}$ & $\mathrm{x}$ \\
\hline & Equal opportunities/discrimination & $\mathrm{x}$ & $\mathrm{x}$ & $\mathrm{x}$ & $\mathrm{x}$ \\
\hline & Health and safety & $\mathrm{x}$ & $\mathrm{x}$ & $\mathrm{x}$ & $\mathrm{x}$ \\
\hline & Social benefits/social security & $\mathrm{x}$ & $\mathrm{x}$ & $\mathrm{x}$ & $\mathrm{x}$ \\
\hline \multirow[t]{5}{*}{ Society } & Public commitments to sustainable issues & $\mathrm{x}$ & $\mathrm{x}$ & $\mathrm{x}$ & $\mathrm{x}$ \\
\hline & Prevention and migration of armed conflicts & - & - & - & - \\
\hline & Contribution to economic development & $\mathrm{x}$ & $\mathrm{x}$ & $\mathrm{x}$ & $\mathrm{x}$ \\
\hline & Corruption & $\mathrm{x}$ & $\mathrm{x}$ & $\mathrm{x}$ & $\mathrm{x}$ \\
\hline & Technology development & $\mathrm{x}$ & $\mathrm{x}$ & $\mathrm{x}$ & $\mathrm{x}$ \\
\hline
\end{tabular}

"," weak "()" or if it does not exist "--". The relationships between social impact and subcategories are defined through an internal brainstorming, (e.g., from the brainstorming it was defined that fair salary strongly impacts the working condition, weakly impacts the workers' health and safety, does not impact the indigenous rights). Then, in order to convert the PA scores for each subcategory into the IA scores, a quantitative approach developed by the authors and based on conventions and best practice is used. Precisely, some values are firstly assigned to the relationship criteria, i.e., 1 point for if the relationship is strong, $1 / 2$ point if the relationship is weak and 0 points if the relationship does not exist; then, for each subcategory, the $\sum \mathrm{IC}$ is evaluated, being the sum of the relationship criteria points related to the impact categories. From PA and $\Sigma I C$, Table 6 reports the conversion rules defined in order to convert the performance assessment into social impacts; in particular, the conversion rules are based on the fact that strong (weak) relations

Table 6 Rules for PA to IA conversion

\begin{tabular}{lllll}
\hline \multicolumn{2}{l}{ Rules of PA to IA } \\
\hline & $\sum \mathrm{IC}<2$ & $2<\sum \mathrm{IC}<4$ & $\sum \mathrm{IC}<4$ & \\
\hline $\mathrm{PA}=1$ & Can turn 2 & 1 & 1 & \\
$\mathrm{PA}=2$ & Can turn 3 & 2 & 1 & $5<\sum \mathrm{IC}<6$ \\
$\mathrm{PA}=3$ & Can turn 4 & 3 & 2 & $4<\sum \mathrm{IC}<5$ \\
& & & 3 & $4<\sum \mathrm{IC}<5$ \\
$\mathrm{PA}=4$ & Can turn 3 & 4 & 4 & $5<\sum \mathrm{IC}<6$ \\
& & & 5 & \\
$\mathrm{PA}=5$ & Can turn 4 & 5 & 6 & \\
$\mathrm{PA}=6$ & Can turn 5 & 6 & 6 & \\
\hline
\end{tabular}


Table 7 Performance assessment and impact assessment scales

\begin{tabular}{|c|c|c|c|}
\hline Performance Assessment & Impact Assessment & Colour & Score \\
\hline Very good performance & Positive effect & & 1 \\
\hline Good performance & Lightly positive effect & & 2 \\
\hline Satisfactory performance & Indifferent effect & & 3 \\
\hline Inadequate performance & Lightly negative effect & & 4 \\
\hline Poor performance & Negative effect & & 5 \\
\hline Very poor performance & Very negative effect & & 6 \\
\hline
\end{tabular}

between categories and performances lead to more positive impacts if the performances are good (bad) and more negative impacts if the performances are bad (good).

Therefore, at each subcategory, the IA can be assigned, ranging from 1 , meaning "positive effect," to 6 , meaning "Very negative effect." At each score, a color is also assigned, as reported in Table 7.

Once the IA of each subcategory is evaluated, the IA of each stakeholder and, finally, the overall IA can be evaluated, for each product life-cycle stage. In particular, the stakeholder IA is assessed as the average score of the IA of all the related subcategories; similarly, the overall IA is assessed as the average score of the IA of all the stakeholders, always considering the additional rule previously described.

Therefore, for the raft alternative solutions, the S-LCA has been performed. The procedure was applied for the traditional and for the innovative rafts.

Table 8 summarizes the IA procedure for each life cycle stage of the traditional and innovative solutions.

From the assessment of the traditional rafts, some observations can be derived. The social impacts are moderately negative for some of the subcategories; for others, indeed, the impacts are very positive, strongly depending on the behavior of the companies. Considering the local community, for each stage of the rafts life cycle, the traditional rafts companies have a high interest in having a local workforce and in spending in local suppliers; nevertheless, they do not engage with community stakeholder groups, do not have policies in place to protect cultural heritage, do not conduct risk assessment with regard to potential for material resource conflict and do not engage with local community over sustainable methods for sharing resources, do not measure air/water/earth pollution nor have laws on Construction Safety Regulations for the community safety and health. Considering the Value Chain Actors, the traditional rafts companies have a high interest in the supplier relationships; on the other hand, documented statements or procedures to prevent engaging in or being complicit in anticompetitive behavior is missing and social responsibility is not promoted. With respect to the Workers, the freedom of association and collective bargaining is guaranteed, child labor and forced labor are forbidden, salary is fair, all the permanent workers receive paid time-off and no occupational safety and health administration violations are reported within the past 3 years; nevertheless, the amount of working hours per day is high, an agreement on paying extra hours is absent, formal policies on equal opportunities are missing, recruitment process only contemplates personal contacts and the workforce is entirely made of men. Moreover, regarding health and safety, the behavior of traditional rafts companies is not always correct. With regard to society, the traditional rafts companies contribute to the economic progress, being the shellfish farming one of the strongest local economic activities; nevertheless, public commitments to sustainable issues are missing; given the risk of corruption absent in this sector, the companies do not carry out anti-corruption programs and do not cooperate with internal and external controls to prevent corruption. Finally, the sector efforts in technology development is quite low and no investments in technology development and technology transfer are made.

From the assessment of the innovative rafts, it can be observed that, in general, the social impacts are better than the in the previous case, and this depends on the company behavior. Indeed, the innovative raft company has a relatively high interest in supporting the local community: on one side, it has a high interest in having a local workforce and in spending in local suppliers, moreover, there are policies in place to protect cultural heritage, such as the restoration of an old precast plant where the rafts are produced and the interest to maintain the traditional production procedures. Nevertheless, on the other side, the company does not engage with local community over sustainable methods for sharing resources nor have a certified environmental management system, it does not measure air/water/earth pollution and private security personnel is absent. With regards to the Value Chain Actors, fair competition is guaranteed, property rights are respected, the relationships with suppliers are good (e.g., no coercive communication is present, lead time is sufficient, volume fluctuations are reasonable and payments to suppliers are on time) and the social responsibility is promoted through the presence of an explicit code. With respect to the workers, freedom of association and collective bargaining is guaranteed, together with the absence of child and forced labor. Working hours and holidays are adequate and salary is fair. Moreover, formal policies on equal opportunities are present, recruitment process is performed through social networks and no incidents 
Table 8 S-LCA impact assessment of the traditional and innovative offshore aquaculture rafts

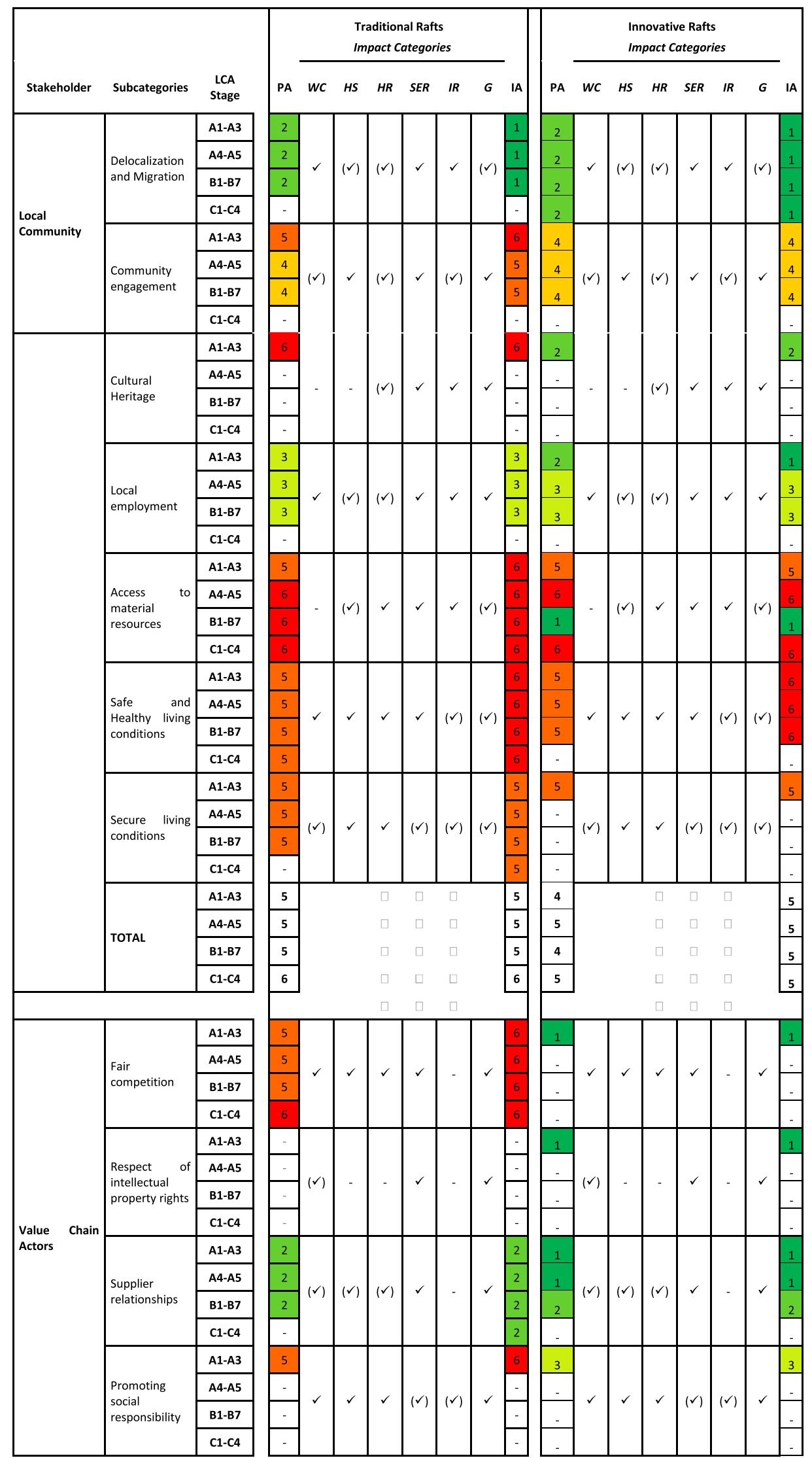


Table 8 (continued)

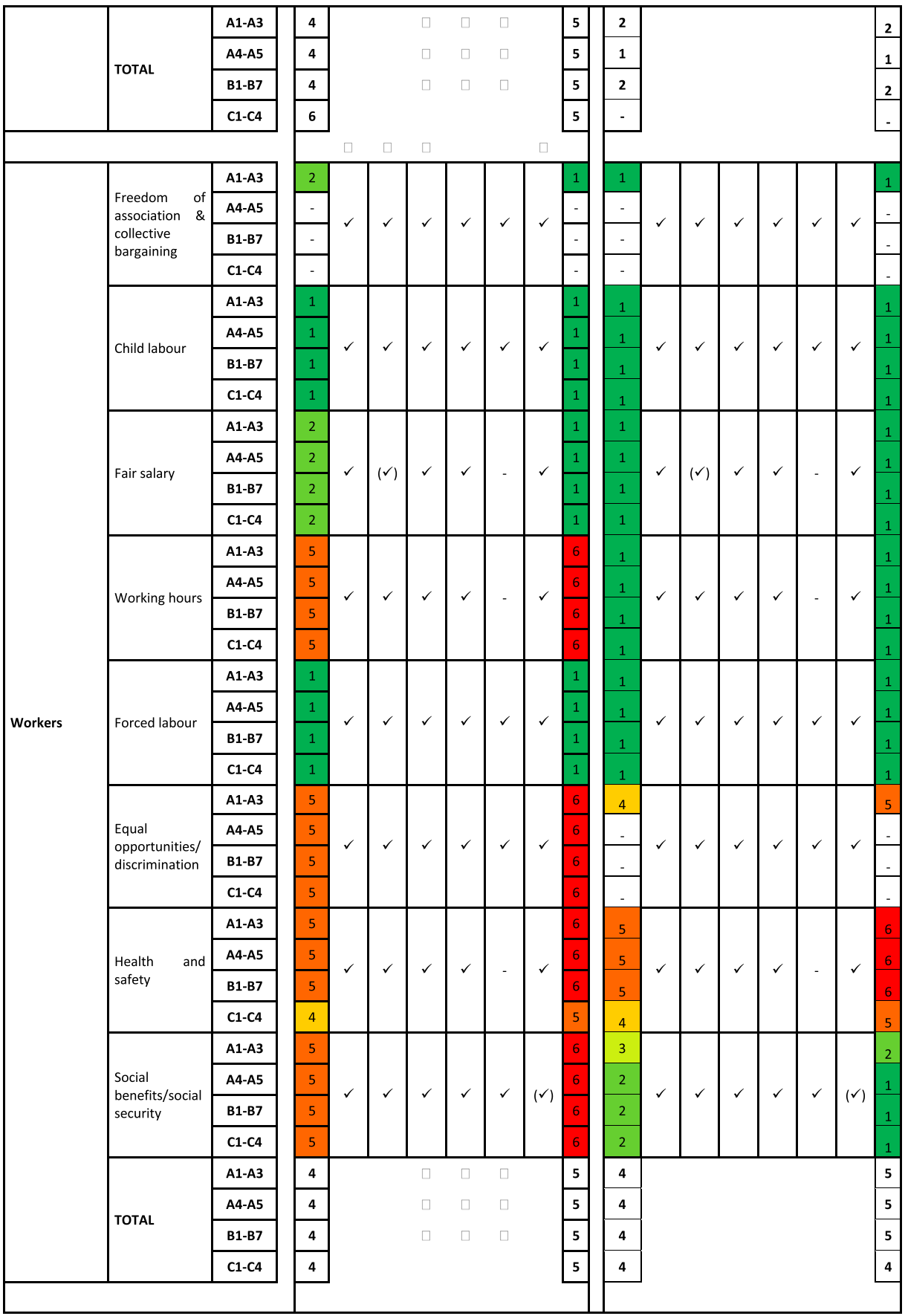


Table 8 (continued)

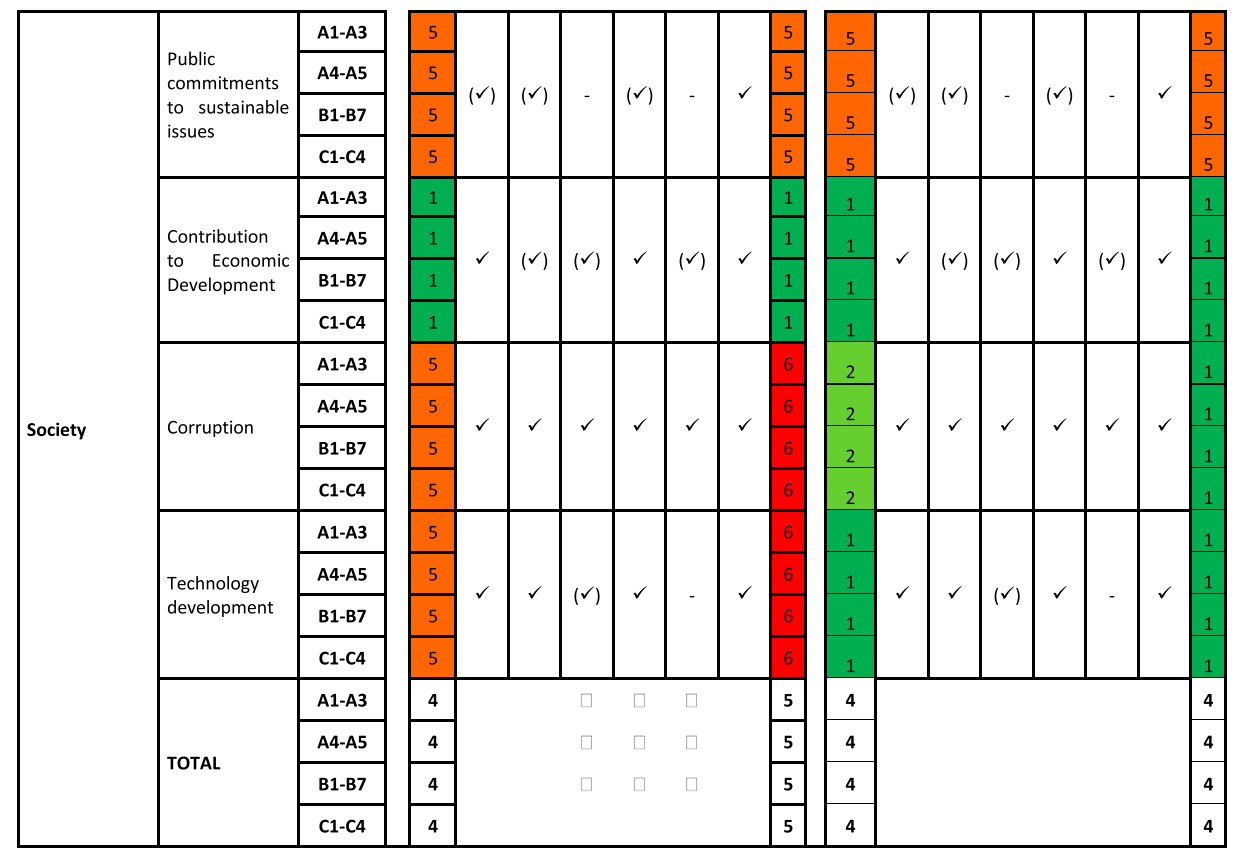

of discrimination happened; nevertheless, no women are hired in the production stage. The behavior of the company is correct when referred to the workers' health and safety (e.g., no injuries or fatal accidents happened, a formal policy concerning health and safety is present, emergency protocols exists and are clear), even if a more effort on the education, training, counselling, prevention and risk control programs should be made in order to guarantee the correct respect of the safety rules. Very few social benefits are given to the workers, but social security is guaranteed. Regarding society, the company contributes to the economic development, corruption is controlled and avoided and technology development is guaranteed through investments and involvement in technology transfer program and projects; nevertheless, public commitments to sustainable issues are missing.

From the total scores deriving from each stakeholder category, the final S-LCA result is evaluated as the average of the total scores, considering each life cycle stage of

Table 9 S-LCA results of the traditional and innovative offshore aquaculture rafts the aquaculture rafts. Final scores are provided in Table 9 and shown in Fig. 9.

It can be observed that the innovative solution for the offshore aquaculture rafts provides a slight social improvement, equal to more than 1 point, on a scale from 1 (positive effect) to 6 (very negative effect). This is basically due to a better behavior of the innovative raft organization regarding the aspects of the community engagement (local community), the fair competition and the promotion of social responsibility (supply chain actors), the working hours and the social benefits/ social security (workers) and, finally, the corruption and the technology development (society); moreover, Table 8 shows that, with some precautions on the behavior related to few subcategories, the social improvement could be even higher.

\subsection{S-LCA conclusions}

The results of the social life cycle assessment report that, comparing the three alternative solutions for the mussel aquaculture structures and the system boundary described in the "Goal and scope" section, the highest social impacts are generated by the traditional rafts, while the lowest social impacts are generated by the innovative raft. Traditional rafts have been assessed together, because the same companies are involved into the rafts life cycle; in particular, the inventory and, consequently, the assessment, is related to 4 traditional rafts companies. From the results shown in Table 9 and in Fig. 9, it can be stated that that the innovative solution can be considered as the solution which is more socially acceptable, when compared to the traditional solutions. 
S-LCA Results for Acquaculture Mussel Raft Solutions

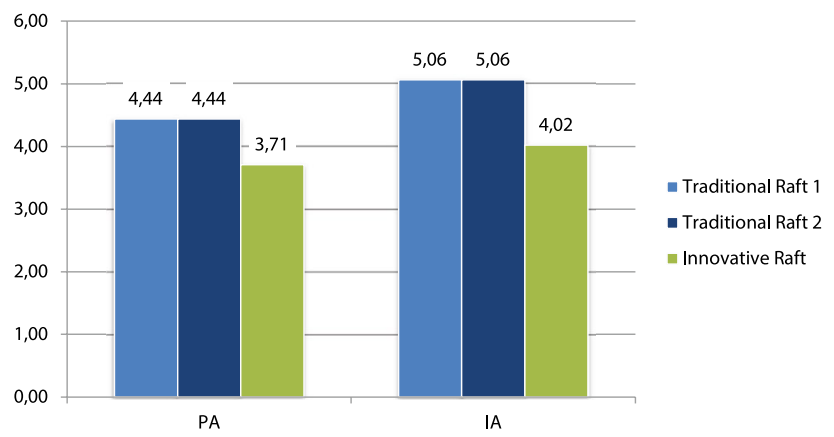

Fig. 9 S-LCA results of the traditional and innovative offshore aquaculture raft

\section{Conclusions}

The EU-funded ReSHEALience Project (GA no. 760824) is working in a more accurate estimation of the durability of structures made of ultra-high performance and ultra high durability concretes (UHPC/UHDC) that can provide longer structural and maintenance free lifetime to structures made of/ retrofitted with them. The performance of structures with these materials is being verified in six pilots located in extremely aggressive environments, i.e., in marine water and/or under chemical attack, in four different European countries (Fig. 1). One of them is a Technology Readiness Level 7 (TRL7) raft that compares with a remote monitoring the performance of its full-scale UHPC and UHDC beams with traditional solutions. As a part of estimating the advantages of these solutions, the present paper verifies the better environmental and social sustainability of an equivalent innovative raft, when compared to two traditional rafts having same functionalities, taking in count the different raft life-spans. For the innovative raft, 50-year life-span has been here considered. The life cycle assessment and the social life cycle assessment methodologies have been used to quantify the environmental and social impacts of the alternative solutions, providing useful scores for comparisons. Two traditional rafts and one innovative raft have been studied, and, in order to have a fair comparison, the same functional unit and the same stages of their life cycle have been considered. The traditional rafts are both made of a wooden primary and secondary beams and have same installation and end-of-life procedures; nevertheless, they differ for the maintenance phase, which is based on logs substitution, for the "Option 1" and on paint application, for the "Option 2." The different maintenance approaches lead to an overall different lifetime, being 23 years for the traditional raft—option 1 and 15 years for the traditional raft-option 2 . The innovative raft is made of UHPC beams, which are designed to last 50 years. Since the other rafts components are the same for the alternative solutions, and the assessment in made in comparative terms, only the rafts platforms are taken in consideration. The data for the inventory stage have been collected with the help of PREFFOR and RDC companies, and checked by STRESS during a site visit. LCA has been performed according to the ISO 14040 and 14,044 with use of the Ecoinvent v3.5 database and Simapro 9.1 software. S-LCA has been performed according to the Guidelines for Social Life Cycle Assessment of Products, the related methodological sheets and the impact assessment method developed by Ciroth and Franze.

From the LCA results, it can be concluded that the highest environmental impacts are generated by the traditional raftoption 2, the lowest environmental impacts are generated by the traditional raft-option 1, while the innovative raft has an intermediate behavior in terms of environmental impact generation. The main responsible of the traditional raft-option 2 impact is the maintenance stage, due to the high frequency and area of the paint application. It should also be noticed that LCAs of the traditional solutions do not include the effects of the degradation of the paint and its dissolution in marine water. From the S-LCA results, it can be concluded that the highest social impacts are generated by the Traditional Rafts, which have been assessed together because the same companies are involved into the rafts life cycle. Lower social impacts are generated by the innovative raft. Social hotspots for the traditional rafts are described in this paper and are referred to the following: the "access to material resources" with respect to the local community; the "fair competition" and the "promotion of social responsibility" with respect to the value chain actors; the "working hours," the "equal opportunities/discrimination," the "health and safety," and the "Social benefits" with respect to the workers; the "public commitments to sustainable issues," the "corruption," and the "technology development" with respect to the society. The social hotspots do not always describe a bad behavior of the companies; indeed, in most of the cases, they reveal the absence of managements systems or policies to prevent it and/or the absence of efforts to reduce the social impacts.

The analysis has also allowed to distinguish the different impacts that different stages (production, construction, use, and end of life) have for the different investigated solutions, the former being less impactful than the latter for traditional rafts and the opposite holding for the innovative one. Similar results are also coming from a preliminary life cycle cost analysis of the rafts grid; indeed, production and construction costs (A1-A5 stages) are around 69,000 $€$ for the innovative raft and 21,000€ for the traditional rafts; nevertheless, if 50 years lifespan is considered, both the options of the traditional raft would cost more than 100,000 $€$ (around 102,000 for Option 1 and around 110,000 for Option 2), whilst the innovative raft would cost around $88,000 €$. All these analyses highlight, in a broader perspective in the civil and building engineering framework, the importance and need of approaching the conceptual and technical design of innovative solutions 
for structures and infrastructures, also employing advanced materials, in a whole and wholesome life cycle perspective. As a matter of fact, this only can enable the different stakeholders involved in the process to have their point of view duly represented and to grasp its importance and impact overall the entire lifespan of the artifact. LCA and S-LCA have been here discussed separately, in order to give the reader a way to look at the rafts sustainability under different points of view. Nevertheless, an approach can be applied for providing a combined social and environmental sustainability score. In this sense, the following forethought should be considered: the results of LCA should be given by using an IA methodology, such as Impact $2002+$, which, through normalization and weighting stages, combine all the environmental impacts into one final score; the life cycle stages included in the analyses should be the same; a weight should be given to both the analyses.

Acknowledgements The present study has been performed in the framework of the project "Rethinking coastal defence and Greenenergy Service infrastructures through enHancEd-durAbiLity highperformance cement-based materials - ReSHEALience," funded by the European Union Horizon 2020 research and innovation program under GA no. 760824.

\section{Declarations}

Conflict of interests The authors declare no competing interests.

Open Access This article is licensed under a Creative Commons Attribution 4.0 International License, which permits use, sharing, adaptation, distribution and reproduction in any medium or format, as long as you give appropriate credit to the original author(s) and the source, provide a link to the Creative Commons licence, and indicate if changes were made. The images or other third party material in this article are included in the article's Creative Commons licence, unless indicated otherwise in a credit line to the material. If material is not included in the article's Creative Commons licence and your intended use is not permitted by statutory regulation or exceeds the permitted use, you will need to obtain permission directly from the copyright holder. To view a copy of this licence, visit http://creativecommons.org/licenses/by/4.0/.

\section{References}

Achten W, Barbeau-Baril J, Barros Telles Do Carmo B, Bolt P, Chandola V, Corona Bellostas B, Dadhish Y, Di Eusanio M, Di Cesare S, Di Noi C, et al (2020) Guidelines for social life cycle assessment of products and organizations. Guidel Soc Life Cycle Assess Prod Organ 2020, 138. Available online: https://www.lifecycleinitiative. org/library/guidelines-for-social-life-cycle-assessment-of-productsand-organisations-2020/. Accessed 2 Feb 2021

Al-Obaidi S, Bamonte P, Luchini M, Mazzantini I, Ferrara L (2020) Durability-based design of structures made with UHP/UHDC in extremely aggressive scenarios: application to a geothermal water basin case study. MDPI Infrastructures 5(11):1-44. https://doi.org/ 10.3390/infrastructures 5110102

CEN. EN 15804:2012+A1 (2013) Sustainability of construction works - environmental product declarations - core rules for the product category of construction products; British Standards Institution: London, UK, 2012

Ciroth A, Franze J (2011) LCA of an ecolabeled notebook. Consideration of social and environmental impacts along the entire life cycle. Berlin: ISBN 978-1-4466-0087-0

Criado M, Gimenez M, Menéndez E, Alonso MC (2020) Durability performance of uncracked and cracked nanoadditioned UHPFRCs in a dynamic leaching system Presented at the 74th RILEM Annual Week and 40th Cement and Concrete Science Conference, Hosted by the University of Sheffield I Online: Zenodo. https:// doi.org/10.5281/zenodo.4289921

Cuenca E, Mezzena A, Ferrara, L (2020) Synergy between crystalline admixtures and nano-constituents in enhancing autogenous healing capacity of cementitious composites under cracking and healing cycles in aggressive waters. Construct Build Mater, paper 121447266 part B:1-17. https://doi.org/10.1016/j. conbuildmat.2020.121447

Cuenca E, D'Ambrosio L, Lizunov D, Tretjakov A, Volobujeva O, Ferrara L (2021a) Mechanical properties and self-healing capacity of ultra high performance fibre reinforced concrete with alumina nano-fibres: tailoring ultra high durability concrete for aggressive exposure scenarios. Cement Concrete Composites 118:103956. https://doi.org/10.1016/j.cemconcomp.2021.103956

Cuenca E, Lo Monte F, Moro M, Schiona A, Ferrara L (2021b) Effects of autogenous and stimulated self-healing on durability 'and mechanical performance of UHPFRC: validation of tailored test method through multi-performance healing-induced recovery indices. MDPI Sustainability 2021(13):1-24. https://doi.org/10. 3390/su132011386

Department of Agriculture, Forestry and Fisheries - Republic of South Africa (2017) Feasibility study of oyster and mussels aquaculture in South Africa. Pretoria, South Africa: Department of Agriculture, Forestry and Fisheries. Available from: https:// www.nda.agric.za/doaDev/sideMenu/fisheries/03_areasofwork/ Aquaculture/economics/Feasibility\%20Study $\% 20$ of $\% 20$ ysters $\%$ 20 and $\% 20$ Mussels $\% 20$ Aquaculture.pdf

Dookstami H, Roig-Flores M, Serna P (2021) Self-healing efficiency of Ultra High-Performance Fiber-Reinforced Concrete through permeability to chlorides. Construct Build Mater 310(125168). https://doi.org/10.1016/j.conbuildmat.2021.125168

European Commission (2013a) Energy-efficient buildings - multiannual roadmap for the contractual PPP under Horizon 2020. 2013 - 141. ISBN 978-92-79-31239-7. https://doi.org/10. $2777 / 29993$

European Commission (2013b) Roadmap for the European Platform on Life Cycle Assessment: facilitating data collection and sustainability assessments for policy and business. Simone Fazio, Marco Recchioni, Camillo De Camillis, Fabrice Mathieux, David Pennington, Karen Allacker, Fulvio Ardente, Lorenzo Benini, Malgorzata Goralczyk, Lucia Mancini, Rana Pant, Serenella Sala, Erwin M. Schau. European Commission, Joint Research Centre, Institute for Environment and Sustainability. https://eplca.jrc.ec.europa.eu/ ELCD3/. Accessed 10 May 2020

European Commission (2016) The European construction sector: a global partner - Internal Market, Industry, Entrepreneurship and SMEs Directorate General, Energy Directorate General, Joint Research Centre (JRC). Available at. https://ec.europa.eu/docsroom/ documents/15866/attachments/1/translations/en/renditions/ native. Accessed 25 Jan 2021

European Commission (2020) The EU Blue Economy Report 2020. Publications Office of the European Union. Luxembourg

Ferrara L, Bamonte P, Falcó CS, Animato F, Pascale C, Tretjakov A, Camacho ET, Deegan P, Sideri S, Gastaldo Brac EM, Serna P, Mechtcherine V, Alonso MC, Peled A, Borg RP (2019) An overview on H2020 project "Reshealience". In: Proceeding IABSE 
Symposium, Guimaraes 2019: Towards a Resilient Built Environment Risk and Asset Management 184-191.

Goedkoop M, Oele M, Leijting J, Ponsioen T, Meijer E (2016) Introduction to LCA with SimaPro. https://www.pre-sustainability. com/download/SimaPro8IntroductionToLCA.pdf. Accessed 10 Feb 2021

International Organization for Standardization (ISO) (2010). ISO 26000:2010 - guidance on social responsibility. Geneva: International Organization for Standardization. From https://www.iso.org/obp/ui/\# iso:std:iso:26000:ed-1:v1:en. Accessed October 23 Oct 2017

Iribarren Lorenzo Diego (2010) Life cycle assessment of mussel and turbot aquaculture application and insights. 588 University of Santiago de Compostela, Spain. ISBN 978-84-9887-420-4

ISO 14044 (2006) Environmental management - life cycle assessment - requirements and guidelines, Brussels: CEN (European Committee for Standardisation)

Lo Monte F, Ferrara L (2020) Tensile behaviour identification in ultrahigh performance fibre reinforced cementitious composites: indirect tension tests and back analysis of flexural test results. Mater Struct 53:145 1-12. https://doi.org/10.1617/s11527-020-01576-8

Lo Monte F, Ferrara L (2021) Self-healing characterization of UHPFRCC with crystalline admixture: experimental assessment via multi-test/multiparameter approach. Constr Build Mater 283:122579. https://doi.org/10.1016/j.conbuildmat.2021. 122579

López JÁ, Coll H, Camacho E, Galán F (2017) Design and fabrication of UHC offshore platforms for mussel farming. Zenodo. https:// doi.org/10.5281/zenodo.839817

Meteogalicia historical data. https://www.meteogalicia.gal/modelos/atlas/ atlasOndas.action?request_locale=es. Accessed May 2019

NF P18-470 (2016) Concrete - ultra-high performance fibre-reinforced concrete - specifications, performance, production and conformity. AFNOR, La Plaine Saint-Denis, 2016

NF P18-710 (2016) National addition to Eurocode 2 - Design of concrete structures: specific rules for ultra-high performance fibre-reinforced concrete (UHPFRC). AFNOR, La Plaine Saint-Denis, 2016
Ozolina Z, Kokaine L (2019) Socioeconomic Impact of Mussel Farming in Coastal Areas of Baltic Sea. Kurzeme Planning Region. Baltic Blue Growth. Available online: https://www. submariner-network.eu/balticbluegrowth. Accessed 2 Feb 2021

Puertos del Estado. https://www.puertos.es/es-es. Accessed May 2019

Serna P,Monte FL, Mezquida-Alcaraz EJ, Cuenca E (2019) Upgrading the Concept of UHPFRC For High Durability in the Cracked State: The Concept of Ultra High Durability Concrete (UHDC) in the Approach of the H2020 Project Reshealience," RILEM Publications SARL V. 128: Sustainable Materials Systems and Structures, SMMS 2019, Croatia, 8 pp. https://doi.org/10.5281/zenodo.2621369

Tamburini E, Turolla E, Fano EA, Castaldelli G (2020) Sustainability of mussel (Mytilus galloprovincialis) farming in the Po River Delta, Northern Italy, based on a life cycle assessment approach. Sustainability 12:3814. https://doi.org/10.3390/su12093814

The International EPD System (2017) General Programme Instructions of the International EPD ${ }^{\circledR}$ System. Version 3.0, dated 2017-12-11

Tirado C, Macias JC (2006) Cultivo de mejillón. Aspectos generales y experiencias en Andalucía (in Spanish). Regional Ministry of Agriculture and Fisheries, Andalucia, Spain

UNEP - SETAC (2009) Life cycle initiative - guidelines for social life cycle assessment of products, United Nations Environment Programme

UNEP - SETAC (2013) Life cycle initiative - the methodological sheets for sub-categories in Social Life Cycle Assessment (S-LCA)

U.S. Department of Energy (2009) U.S. life cycle inventory data roadmap. Washington, DC: National Renewable Energy Laboratory. http://www.nrel.gov/lci/pdfs/45153.pdf. Accessed 10 Feb 2021

Wernet G, Bauer C, Steubing B, Reinhard J, Moreno-Ruiz E, Weidema B (2016) The Ecoinvent database version 3 (part I): overview and methodology. Int J Life Cycle Assess [online] 21(9):1218-1230. Available at. http://link.springer.com/10.1007/s11367-016-1087-8

Publisher's Note Springer Nature remains neutral with regard to jurisdictional claims in published maps and institutional affiliations.

\section{Authors and Affiliations}

\section{Maria Chiara Caruso $^{1}$ (1) $\cdot$ Carmine Pascale $^{1} \cdot$ Esteban Camacho $^{2} \cdot$ Liberato Ferrara $^{3}$}

1 Sviluppo Tecnologie e Ricerca per l'Edilizia Sismicamente Sicura ed Ecosostenibile S.c.ar.1. (STRESS) - Vico II S. Nicola alla Dogana 9, 80133 Napoli, Italy

2 Research \& Development Concretes SL (RDC) - Conde De Altea 52-3, 46005, Valencia, Spain
3 Department of Civil and Environmental Engineering, Politecnico di Milano - Piazza Leonardo da Vinci 32, 20133 Milano, Italy 